\title{
STUDY ON BIOCHEMICAL CHANGES IN EXFOLIATIVE DERMATITIS
}

\author{
ISLAM $\mathrm{S}^{1}$, ISLAM AKMA ${ }^{2}$, SULTANA ${ }^{3}$, HOSSAIN MZ ${ }^{4}$
}

\begin{abstract}
:
A study was carried out in the Department of Dermatology and Venereology, Bangabandhu Sheikh Mujib Medical University (BSMMU) for a period of six months from April to September 2007. 50 patients with exfoliative dermatitis were included in the study according to the inclusion and exclusion criteria. Biochemical changes were detected by collection of blood sample and sending it for biochemical studies. The male and female ratio was 3.17:1. The study showed that 24\% patients were anaemic, 44\% had raised ESR, 28\% had lower serum total protein, 40\% had decreased serum albumin, 10\% had an altered A:G ratio, $8 \%$ had raised serum creatinine, $12 \%$ had raised blood urea, 12\% had raised SGPT, 10\% had raised RBS, 16\% had showed decreased serum calcium, 18\% had hyponatraemia, 12\% had hypokalaemia and $6 \%$ had hypochloraemia.
\end{abstract}

Key words: Exfoliative dermatitis, biochemical change.

J Dhaka Med Coll. 2009; 18(2) : 127-131

\section{Introduction:}

Exfoliative dermatitis (ED) is a definitive term that refers to a scaling erythematous dermatitis involving $90 \%$ or more of the cutaneous surface. ED is characterized by erythema and scaling involving the skin's surface and often obscures the primary lesions that are important clues to understanding the evolution of the disease ${ }^{1}$. Erythroderma is the condition where multisystem may be involved. The widespread inflammatory and exfoliative eruption produces secondary effects on the other organ systems and on the body as a whole, some of which can be quite debilitating ${ }^{2}$. The metabolic disturbances involve a serious risk of hypothermia, edema, hypervolemia, negative nitrogen, potassium and folate balances, hypokalemia, hypocalcemia, cardiac compensation, high output cardiac failure and thrombophlebitis ${ }^{3}$. As these biochemical changes due to secondary hemodynamic derangements may lead to severe complications, or even fatal condition to the patient, so the study was aimed to detect the biochemical abnormalities. This may be helpful in practice in that way that the patient can be managed properly as well as complications can be prevented.
Materials and Methods:

It is an observational (cross sectional, descriptive) type of study. Fifty (50) patients with clinically and in some cases histopathologically diagnosed exfoliative dermatitis were included in study in the period of six months from April to September 2007 at the Department of Dermatology \& Venereology, Bangabandhu Sheikh Mujib Medical University (BSMMU), Dhaka. Sampling technique was purposive sampling. Patients with clinical diagnosis of exfoliative dermatitis of both sexes and of any age and willing to give informed consent were included in the study. Patients not willing to be included in the study or already enrolled in any other similar type of study or patients with any other condition which is likely to influence the biochemical markers were excluded from the study. A detail history was taken and a thorough clinical examination of the patient was done. The area of cutaneous involvement was observed carefully to ensure that $90 \%$ or more of the patients' skin is involved. A patient was included in the study only after meeting all the inclusion criteria. A blood sample was collected and sent for biochemical examination. The patients' data was recorded in the pre-designed case report

1. Emergency Medical Officer, Infectious Diseases Hospital, Dhaka.

2. Registrar, Department of Respiratory Medicine, Dhaka Medical College Hospital, Dhaka.

3. Assistant Professor, Department of Dermatology, BSMMU, Dhaka.

4. Assistant Professor, Department of Medicine, Dhaka Medical College.

Correspondence: Shiropa Islam 
form (CRF). The data was analyzed using standard statistical methods.

\section{Results:}

Though the objective of the study is to determine the biochemical change in patients with exfoliative dermatitis, a few other relevant data were collected such as age and sex distribution, temperature etc. Of the 50 patients enrolled, 38 patients were male $(76 \%)$ and 12 were female $(24 \%)$ with a male: female ratio 3.16:1. Age of the patients ranged from 079 years and the patients were divided into 8 age groups. The data reveals that maximam patients were of $50-59$ years age group. $52 \%$ of the patients presented with normal temperature while $30 \%$ of them presented with hyperthermia and interestingly $18 \%$ with hypothermia. Anemia was present in 37 cases $(74 \%)$ and 13 cases $(26 \%)$ were not anemic (normal $\mathrm{Hb} \%$ is $13-17 \mathrm{gm} / \mathrm{dl}$ in case of male and $11-15.5 \mathrm{gm} / \mathrm{dl}$ in case of female). Of the 37 patients who had anemia, 25 patients $(50 \%)$ were mildly anemic, 5 patients (10\%) were moderately anemic and 2 patients (4\%) were severely anemic. 22 (44\%) of the patients had raised ESR, but the rest twenty eight patients $(56 \%)$ had normal ESR $\left(0-12 \mathrm{~mm}\right.$ in $1^{\text {st }}$ hour in male and $0-18 \mathrm{~mm}$ in $1^{\text {st }}$ hour in female).
Creatinine levels were within normal limit (44-110 micromole/L) in most of the patients $(92 \%)$, while a few $(8 \%)$ presented with a raised serum creatinine. Only 6 patients $(12 \%)$ had high blood urea levels while the rest 44 patients $(88 \%)$ had normal blood urea levels (2.5$7.5 \mathrm{mmol} / \mathrm{L}$ ). There was decreased serum total protein in $28 \%$ of the patients while the rest $72 \%$ patients revealed normal serum total protein $(6.4-8.3 \mathrm{gm} / \mathrm{dl}) .30$ out of 50 patients $(60 \%)$ presented with normal serum albumin (3.8-4.4 gm/dl) and 20 patients (40\%) presented with reduced serum albumin (hypoalbuminemia). Normal Albumin: Globulin ratio (1.2:1-2.5:1) was revealed in $90 \%$ of patients while Albumin:Globulin ratio was altered in $10 \%$ patients. 45 patients (90\%) had their blood sugar level within normal limit and only 5 patients $(10 \%)$ showed hyperglycemia. Hyponatraemia were present in $18 \%$ of patients, hypokalemia in $12 \%$ of patients and hypochloraemia were present in $6 \%$ of patients. No patient showed any abnormality in bicarbonate levels. Serum calcium levels were decreased in $16 \%$ of patients and were normal in the remaining $84 \%$ of patients. SGPT levels were normal in 44 patients $(88 \%)$ and the rest 6 patients (12\%) had raised SGPT levels.

Table-I

Age and sex distribution of patients of exfoliative dermatitis $(N=50)$

\begin{tabular}{lcccccc}
\hline \multirow{2}{*}{ Age Group } & \multicolumn{2}{c}{ Male (38) } & \multicolumn{2}{c}{ Female (12) } & \multicolumn{2}{c}{ Total } \\
\cline { 2 - 7 } & No & $\%$ & No & 0 & No & $\%$ \\
\hline 0-9years & 2 & $4 \%$ & 0 & $0 \%$ & 2 & $4 \%$ \\
10-19 years & 0 & $0 \%$ & 0 & $0 \%$ & 0 & $0 \%$ \\
20-29 years & 2 & $4 \%$ & 0 & $0 \%$ & 2 & $4 \%$ \\
30-39 years & 2 & $4 \%$ & 1 & $2 \%$ & 3 & $6 \%$ \\
40-49 years & 8 & $16 \%$ & 2 & $4 \%$ & 10 & $20 \%$ \\
50-59 years & 13 & $40 \%$ & 6 & $12 \%$ & 19 & $38 \%$ \\
60-69 years & 9 & $18 \%$ & 2 & $4 \%$ & 11 & $22 \%$ \\
$70-79$ years & 1 & $2 \%$ & 1 & $2 \%$ & 2 & $4 \%$ \\
80-89 years & 1 & $2 \%$ & 0 & $0 \%$ & 1 & $2 \%$ \\
\hline Total & 38 & $76 \%$ & 12 & $24 \%$ & 50 & $100 \%$ \\
\hline
\end{tabular}


Table-II

Anemia associated with exfoliative dermatitis $(N=50)$

\begin{tabular}{lcccccc}
\hline Variables & \multicolumn{2}{c}{ Male (38) } & \multicolumn{2}{c}{ Female (12) } & \multicolumn{2}{c}{ Total } \\
& No & $\%$ & No & $\%$ & No & $\%$ \\
\hline No anemia & 12 & $24 \%$ & 1 & $2 \%$ & 13 & $26 \%$ \\
Mild anemia & 19 & $38 \%$ & 6 & $12 \%$ & 25 & $50 \%$ \\
Moderate anemia & 5 & $10 \%$ & 5 & $10 \%$ & 10 & $20 \%$ \\
Severe anemia & 2 & $4 \%$ & 0 & $0 \%$ & 2 & $4 \%$ \\
\hline
\end{tabular}

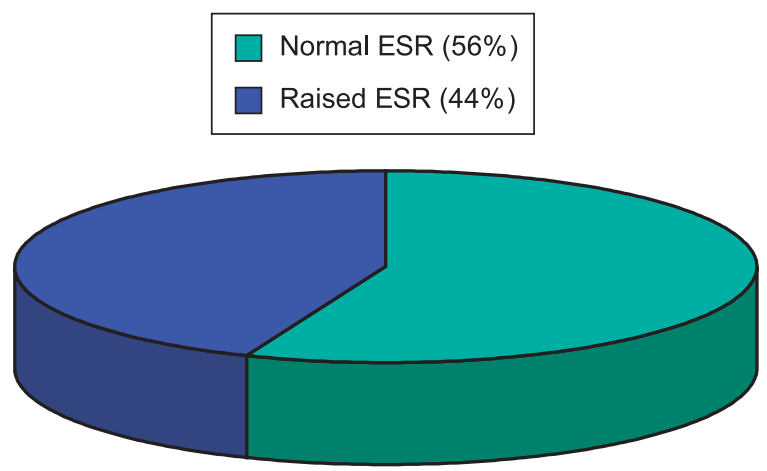

Fig.-1: Pie chart showing ESR in exfoliative dermatitis.

Table-III

Serum Creatinine levels in Exfoliative Dermatitis $(n=50)$.

\begin{tabular}{lcccccc}
\hline Variables & \multicolumn{2}{c}{ Male (38) } & \multicolumn{2}{c}{ Female (12) } & \multicolumn{2}{c}{ Total } \\
& No & $\%$ & No & $\%$ & No & $\%$ \\
\hline $\begin{array}{l}\text { Normal } \\
\text { Creatinine }\end{array}$ & 34 & $68 \%$ & 12 & $24 \%$ & 46 & $92 \%$ \\
$\begin{array}{l}\text { Raised } \\
\text { Creatinine }\end{array}$ & 4 & $8 \%$ & 0 & $0 \%$ & 4 & $8 \%$ \\
\hline
\end{tabular}

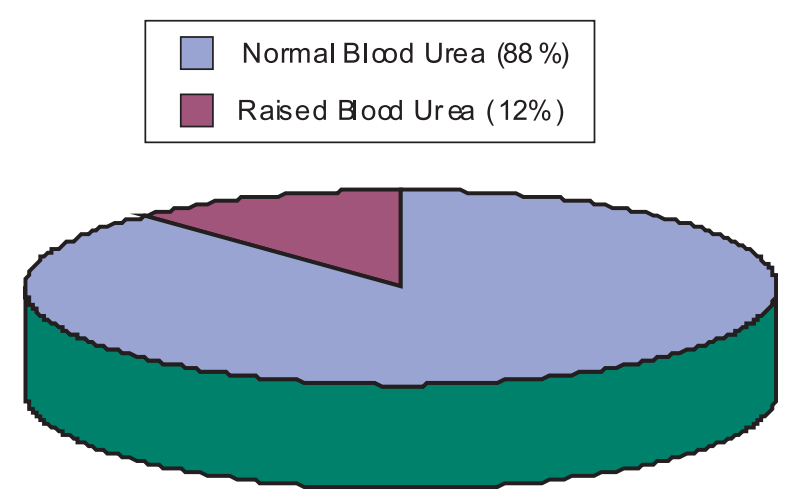

Fig.-2: Pie chart showing blood urea levels in exfoliative dermatitis.
Table-IV

Serum Total Protein in Exfoliative

Dermatitis $(n=50)$

\begin{tabular}{lcccccc}
\hline Variables & \multicolumn{2}{c}{ Male (38) } & \multicolumn{2}{c}{ Female (12) } & \multicolumn{2}{c}{ Total } \\
& No & $\%$ & No & $\%$ & No & $\%$ \\
\hline $\begin{array}{l}\text { Normal } \\
\text { Serum Total }\end{array}$ & 27 & $54 \%$ & 9 & $18 \%$ & 36 & $72 \%$ \\
$\begin{array}{l}\text { Protein } \\
\text { Decreased } \\
\begin{array}{l}\text { Serum Total } \\
\text { Protein }\end{array}\end{array}$ & 11 & $22 \%$ & 3 & $6 \%$ & 14 & $28 \%$ \\
\hline
\end{tabular}

Table-V

Serum Albumin Levels in Exfoliative Dermatitis $(n=50)$

\begin{tabular}{lcccccc}
\hline Variables & \multicolumn{2}{c}{ Male (38) } & \multicolumn{2}{c}{ Female (12) } & \multicolumn{2}{c}{ Total } \\
& No & $\%$ & No & $\%$ & No & $\%$ \\
\hline Normal & 22 & $44 \%$ & 8 & $16 \%$ & 30 & $60 \%$ \\
$\begin{array}{l}\text { Serum } \\
\text { Albumin }\end{array}$ & & & & & & \\
$\begin{array}{l}\text { Decreased } \\
\text { Serum } \\
\text { Albumin }\end{array}$ & 16 & $32 \%$ & 4 & $8 \%$ & 20 & $40 \%$ \\
\hline
\end{tabular}

Table-VI

Albumin:Globulin (A:G) Ratio in Exfoliative Dermatitis $(n=50)$

\begin{tabular}{lcrcccc}
\hline Variables & \multicolumn{2}{c}{ Male (38) } & \multicolumn{2}{c}{ Female (12) } & \multicolumn{2}{c}{ Total } \\
& No & $\%$ & No & $\%$ & No & $\%$ \\
\hline Normal & 34 & $68 \%$ & 11 & $22 \%$ & 45 & $90 \%$ \\
A:G Ratio & & & & & & \\
Altered & 4 & $8 \%$ & 1 & $2 \%$ & 5 & $10 \%$ \\
A:G Ratio & & & & & & \\
\hline
\end{tabular}

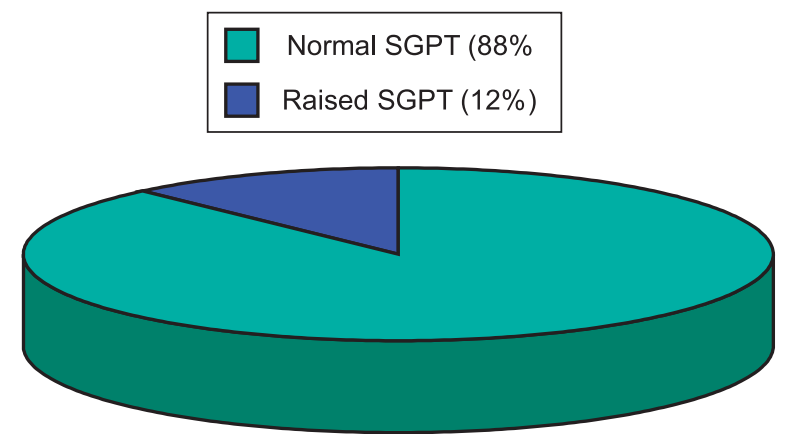

Fig.-3: Pie chart showing SGPT levels in exfoliative dermatitis 
Table-VII

Blood Sugar Levels in Exfoliative Dermatitis $(n=50)$

\begin{tabular}{lcccccc}
\hline Variables & \multicolumn{2}{c}{ Male (38) } & \multicolumn{2}{c}{ Female } & $(12)$ & \multicolumn{2}{c}{ Total } \\
& No & $\%$ & No & $\%$ & No & $\%$ \\
\hline Normal RBS & 34 & $68 \%$ & 11 & $22 \%$ & 45 & $90 \%$ \\
Raised RBS & 4 & $8 \%$ & 1 & $2 \%$ & 5 & $10 \%$ \\
\hline
\end{tabular}

Table-VIII

Serum calcium levels in exfoliative dermatitis $(n=50)$

\begin{tabular}{lcccccc}
\hline Variables & \multicolumn{2}{c}{ Male (38) } & \multicolumn{3}{c}{ Female (12) } & \multicolumn{2}{c}{ Total } \\
& No & $\%$ & No & $\%$ & No & $\%$ \\
\hline $\begin{array}{l}\text { Normal Serum } \\
\text { Calcium }\end{array}$ & 33 & $66 \%$ & 9 & $18 \%$ & 42 & $84 \%$ \\
$\begin{array}{l}\text { Decreased } \\
\text { Serum Calcium }\end{array}$ & 5 & $10 \%$ & 3 & $6 \%$ & 8 & $16 \%$ \\
\hline
\end{tabular}

Table-IV

Serum electrolyte in exfoliative dermatitis $(n=50)$

\begin{tabular}{llcccccc}
\hline Variables & & \multicolumn{2}{c}{ Male (38) } & \multicolumn{2}{c}{ Female (12) } & \multicolumn{2}{c}{ Total } \\
& & No & $\%$ & No & $\%$ & No & $\%$ \\
\hline \multirow{2}{*}{ Sodium } & Normal & 31 & $62 \%$ & 10 & $20 \%$ & 41 & $82 \%$ \\
& Reduced & 7 & $14 \%$ & 2 & $4 \%$ & 9 & $18 \%$ \\
\multirow{3}{*}{ Chloridium } & Normal & 34 & $68 \%$ & 10 & $20 \%$ & 44 & $88 \%$ \\
& Reduced & 4 & $8 \%$ & 2 & $4 \%$ & 6 & $12 \%$ \\
& Normal & 35 & $70 \%$ & 12 & $24 \%$ & 47 & $94 \%$ \\
& Reduced & 3 & $6 \%$ & 0 & $0 \%$ & 3 & $6 \%$ \\
& Normal & 38 & $76 \%$ & 12 & $24 \%$ & 50 & $100 \%$ \\
& Reduced & 0 & $0 \%$ & 0 & $0 \%$ & 0 & $0 \%$ \\
\hline
\end{tabular}

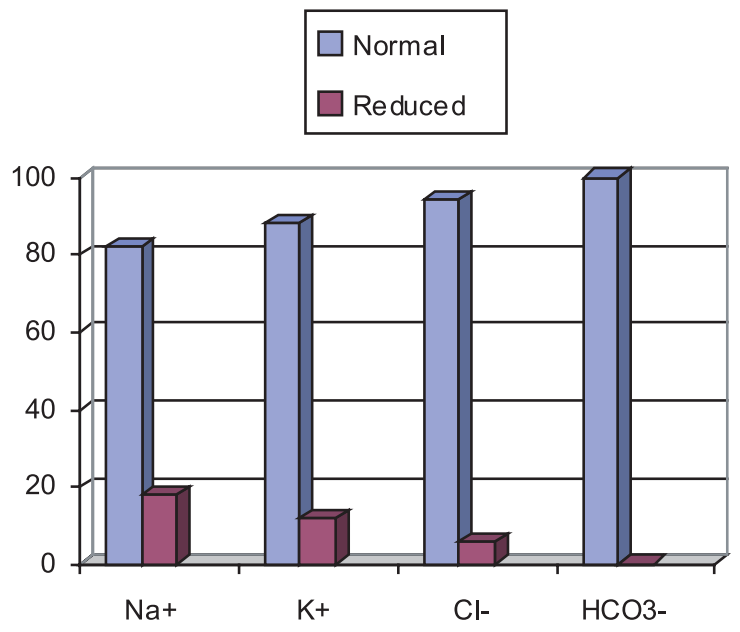

Fig.-4: Bar chart showing serum electrolyte levels in exfoliative dermatitis.

\section{Discussion:}

The biochemical changes in exfoliative dermatitis are widely variable in different studies. In the present study, lowered serum total protein level (28\%) is found to be compatible with the findings by Botella et $\mathrm{al}^{1}$ $(34 \%)$ but is dissimilar with the findings by Sehgal and Srivastava ${ }^{2} \quad(12.5 \%)$.
Hypoalbuminemia results from decreased synthesis, elevated catabolism to compensate for protein loss, and hypervolemia. $40 \%$ of the study patients with decreased serum albumin level support the pathology. It is in contrast with the findings of Worm et al. (1981) ${ }^{3}$ in which case it was $51 \%$ but matches the findings of Wong KS et al. (1988) ${ }^{4}$ which was $42 \%$. Lowered serum sodium and potassium is due to increased transepidermal water loss. Hyponatremia and hypokalemia were observed in $18 \%$ and $12 \%$ respectively in the study. It is in contrast with the findings of Hassan and Jansen $(1983)^{5}$ which was $26 \%$ and $18 \%$ respectively and in conformity with the finding of Wong et al. (1988) ${ }^{4}$ in which case it was $17 \%$ and $14 \%$ respectively. Increased fluid losses from both the greater transepidermal water loss and the higher basal metabolic rate may result in dehydration and subsequently renal insufficiency. Raised serum creatinine level in $8 \%$ of patients and raised blood urea level in $12 \%$ of patients support the issue. Nicolis and Helwig ${ }^{6}$ found raised serum creatinine and blood urea levels as $15 \%$ and $21 \%$ respectively which is different from the findings of present 
study. Random blood sugar was found to be raised in only $10 \%$ of patients as patients with any other condition, which is likely to affect the biochemical markers, were excluded from the study. Hence patients with Diabetes mellitus were excluded from the study. Other than biochemical variables, some important physical and haematological findings were also noticed in the study. Cervical and / or inguinal lymphadenopathy was found in $28 \%$ patients. Bilateral leg oedema was found in $48 \%$. Out of 50 patients, hepatomegaly was found in 5 patients $(10 \%)$ and spleenomegaly in 2 patients (4\%). Patients with exfoliative dermatitis develop poikilothermia. In this study, $30 \%$ of patients were found to have hyperthermia whereas another $18 \%$ of patients were found to be hypothermic which supports the failure of compensatory mechanism for ambient temperature changes in exfoliative dermatitis ${ }^{7}$. The study result is similar to that of the study conducted by Fox et al. ${ }^{8}$ and Grice and Bettley ${ }^{9}$. Mild to severe anaemia were present in $74 \%$ of patients. But it is difficult to ascertain whether the anaemia was directly related to the disease. Raised ESR was found in $44 \%$ of patients. But ESR may rise in many other conditions and hence can't be explained by the disease process alone. The finding is similar to the findings of Abrahams et al. ${ }^{7}$ and King et al. ${ }^{10}$. Leucocytosis was found in $26 \%$ of patients. Differential count of eosinophil was found to be raised in $32 \%$ of patients. Lymphocytosis, found as $16 \%$ in the study, closely matches the findings of Vossbeck et al. ${ }^{11}$ which was $18 \%$ but does not match the results of the study conducted by King et $\mathrm{al}^{10}$ in 1986 (42\%).

\section{Conclusion:}

The study results have similarities as well as dissimilarities with the results of the similar studies performed earlier home and abroad. But the ultimate truth that came out of the study is that the Bangladeshi patients suffering from exfoliative dermatitis are not free from the biochemical alterations and their lifethreatening consequences.

\section{References:}

1. Botella-Estrada R, Sanmartin O, Oliver V, Febrer I, Aliaga A. Erythroderma: a clinicopathological study of 56 cases. Arch Dermatol. 1994; 130(12): 1503-7.

2. Sehgal VN, Srivastava G. Exfoliative dermatitis: a prospective study of 80 patients. Dermatologica. 1986; 173(6): 278-84.

3. Worm AM, Taaning E, Rossing N. Distribution and degradation of albumin in extensive skin disease. Br J Dermatol. 1981; 104(4): 389-96.

4. Wong KS, Wong SN, Tham SN, Giam YC. Generalized exfoliative dermatitis: a clinical study of 108 patients. Ann Acad Med Singapore. 1988;17(4): 520-3.

5. Hasan T, Jansen CT. Erythroderma: a follow-up of fifty cases. J Am Acad Dermatol. 1983; 8: 83640 .

6. Nicolis GD, Helwig EB. Exfoliative dermatitis: a clinicopathologic study of 135 cases. Arch Dermatol. 1973; 108: 788-97.

7. Abrahams I, McCarthy JT, Sanders SL.101 cases of exfoliative dermatitis. Arch Dermatol. 1963; 87: 96-101.

8. Fox RH, Shuster S, Williams R, Marks J, Goldsmith R, Condon RE. Cardiovascular, metabolic and thermoregulatory disorders in patient with erythrodermic skin disease. BMJ. 1965; 1: 619-22.

9. Grice KA, Bettley FR. Skin water loss and accidental hypothermia in psoriasis, ichthyosis and erythroderma. BMJ. 1967; 4: 195-8.

10. King LE, Dufresne RG, Lovett GL, Rosin MA. Erythroderma: review of 82 Cases. South Med J. 1986; 79: 1210-5.

11. Vossbeck S, Knobloch C, Heymer B, Hartmann W, Friedrich W. Severe combined immune defect: presentation of exfoliative dermatitis with eosinophilia and lymphadenopathy. [Article in German] [Abstract]. Monatsschr Kinderheilkd. $1992 ; 140(3): 188-93$. 